\title{
SMALL IS BEAUTIFUL BUT SMALLER IS THE AIM: REVIEW OF A LIFE OF RESEARCH
}

\author{
A.S.G. Curtis \\ Centre for Cell Engineering, University of Glasgow, Scotland
}

\begin{abstract}
Background and origins of research of Adam Curtis. One persisting theme has been the pursuit of different landscapes at different scales to discover the routes to explain how the body is built. His research life fell in a fortunate period during which techniques and concepts for investigating structure have improved year by year. His most fortunate encounter was with Michael Abercrombie and his views on the social behaviour of cells, aims for quantitation, and statistical testing. Adam worked in various environments in turn Geology as an undergraduate, Biophysics Ph.D. in a Genetics department and various departments in turn from anatomy via zoology to Cell Biology. Adam started his $\mathrm{Ph} . \mathrm{D}$. work in cell adhesion, studying cell movement, trapping and reaggregation phenomena, having an early start from the physico-chemical viewpoint. He made quantitative measurements of cell adhesion by kinetic methods. Interference reflection microscopy (IRM) and related optical interference techniques were brought into the field of biology by him. In turn this led with Chris Wilkinson, a long term colleague, to the use of micro- and nanofabrication for biological research. Polscope and photoelastic measurements were introduced to biology recently in his laboratory. One long term theme has been to map the adhesion of cells to substrates to discover contact areas. Early data came from IRM and then TIRF (Total Internal Reflection Fluorescence Microscopy) and then from Forster Resonance Energy Microscopy (FRET). Another important theme was the time scale that needed to be measured - very short indeed in suspension. This was very difficult and has only become possible very recently but hydrodynamic calculation shows it must be very short. The attractions of the Derjagin-Landau-Verwey-Overbeek theory (DLVO theory) are that they explain many features of biological adhesion. The main test of this theory depends upon the energy of the adhesion at various different separation distances between cell and cell or cell and substrate. Problems with cell adhesion molecules are discussed. Contact guidance of cells by oriented structures and Paul Weiss - Tests with grating replicas suggested that topographic rather than biochemical explanations were applicable. It became clearer later that this was an area of research waiting for microfabrication. Albert Harris influenced me considerably to start thinking about mechanical forces produced by cells. Pulling at cells showed effects on the cytoskeleton and on cell cycle time. Such thoughts led to a microfabricated device for tendon repair. Recent photoelastic measurements with the Polscope have allowed much more detailed analysis of the forces between cells. The interesting results on microfabricated devices led
\end{abstract}

to work on nanostructures. Results led the Glasgow group to consider dimensions of structures and how cells could sense such small objects and questions about why order and size may be important. Differential protein adsorption onto surfaces seems to provide defective explanations of the effects. The results will be discussed in terms of very recent theories of cell interaction and cell signals and possible future developments will be outlined.

Key Words: Adam Curtis, Glasgow, cell adhesion, microfabrication, nanofabrication, nanotopography, neuronal networks, tendon.

Address for correspondence:

A.S.G. Curtis

Centre for Cell Engineering,

University of Glasgow, Glasgow, G12 8QQ, U.K.

Telephone number: +44 141330 5147]

FAX Number: +44 1413303730

E-mail: A.Curtis@bio.gla.ac.uk

\section{Introduction}

The research I shall describe was conducted over a considerable period. Whilst it will mention results from many interactions with other people and with new techniques, this paper will not concentrate on the history of people and places, so much as on a description of the research landscape and on why it has been worthwhile staying in the same research country - even if it moves from place to place within that landscape- and why I have always wanted to explore it further. In the process of describing that landscape and the roads and paths within it I shall remark on some as yet unexplored paths and where they might lead. Not all useful interactions with people and places will be described. I started research as a Ph.D. student at the Institute of Animal Genetics University of Edinburgh with Professor C.H. Waddington and Dr Geoffrey Selman as supervisors and my topic was Some Biophysical Studies of Cell Adhesion. At the start of the thesis there were some twelve papers in the subject.

\section{Adhesion}

The work of Dan on the adhesion of sea urchin eggs (Dan, 1947) had shown that counterion valencies and concentrations could play a very important role in determining whether adhesion could or could not occur. 
Reading about this led me to H.R. Kruyt's (1949, 1952) massive two volume compilation on colloid science which emphasised the role of electrostatic and electrodynamic forces in determining particle adhesion and helped me develop the concept of much of cell adhesion being determined by a force balance in the secondary minimum of the potential energy diagram. This concept is explained well in the paper by Bongrand's group (Vitte et al., 2004). Kruyt's colleagues Verwey and Overbeek had been involved in $50 \%$ of the development of what is now known as the DLVO theory (Derjaguin, Landau, Verwey and Overbeek). What was known about the dimensions of cell contacts, the fairly free flow and diffusion within intercellular fluids was consistent with the idea of a secondary minimum adhesion - though non-biophysicists have found this concept difficult. I therefore pursued that concept and this led to the use of interference reflecting systems as in some metallurgical microscopes to look at the separation between cell and substratum, further leading to the introduction of IRM to biological work (Curtis 1964). In turn, but not in our hands, that led to the discovery of the focal contact (Izzard and Lochner, 1976). The IRM results were consistent with DLVO interpretations (Figs. $1-3)$

IRM was, in fact, not quite good enough in z-axis measurement at small separations but it did confirm that the refractive indices of the plasmalemma were close to 1.35 and the intervening medium close to 1.34 . Why did we make that claim? Reflectivity values (Contrast values) would not be consistent with the observed image if anything more than very small deviations from these values were allowed. I should mention that the late David Gingell inspired me and to a large extent examined the IRM system in detail (Gingell, 1981). Gingell, before his early untimely death, was much involved in the development of a parallel system the TIRF microscope. I have not left the field entirely alone, since H. Morgan looked at the idea that surface plasmon resonance could be used to measure the dimensions of adhesions (Zhang et al., 2001) and I have tried to use FRET microscopy to look at the resonance coupling that could occur from one membrane to another. FRET microscopy should provide a very accurate measurement of membrane to substratum proximity in the 1-6nm range. I was, and still am, concerned about the manner in which the adhesion of the cells should be measured.

Measurements of the force that needs to be applied to break an adhesion are quite widely used but have several defects (Curtis and Lackie, 1991; Bongrand et al., 1994; Richards et al., 1995). Taking a leaf from the books of the colloid chemists, it seemed sensible to adopt their concept of the probability that a collision between cell and cell or cell and substrate leads to an adhesion, in other words collision probability. Very adhesive cells would have a collision probability of $100 \%$. This measure is of course a measurement of the formation of an adhesion. It has several attractions as a measure. First it can be tied into the hydrodynamic and other forces involved in forming an adhesion (Swift and Friedlander, 1964; Duszyk and Doroszewski, 1986; Doroszewski and Kiwala, 1988),
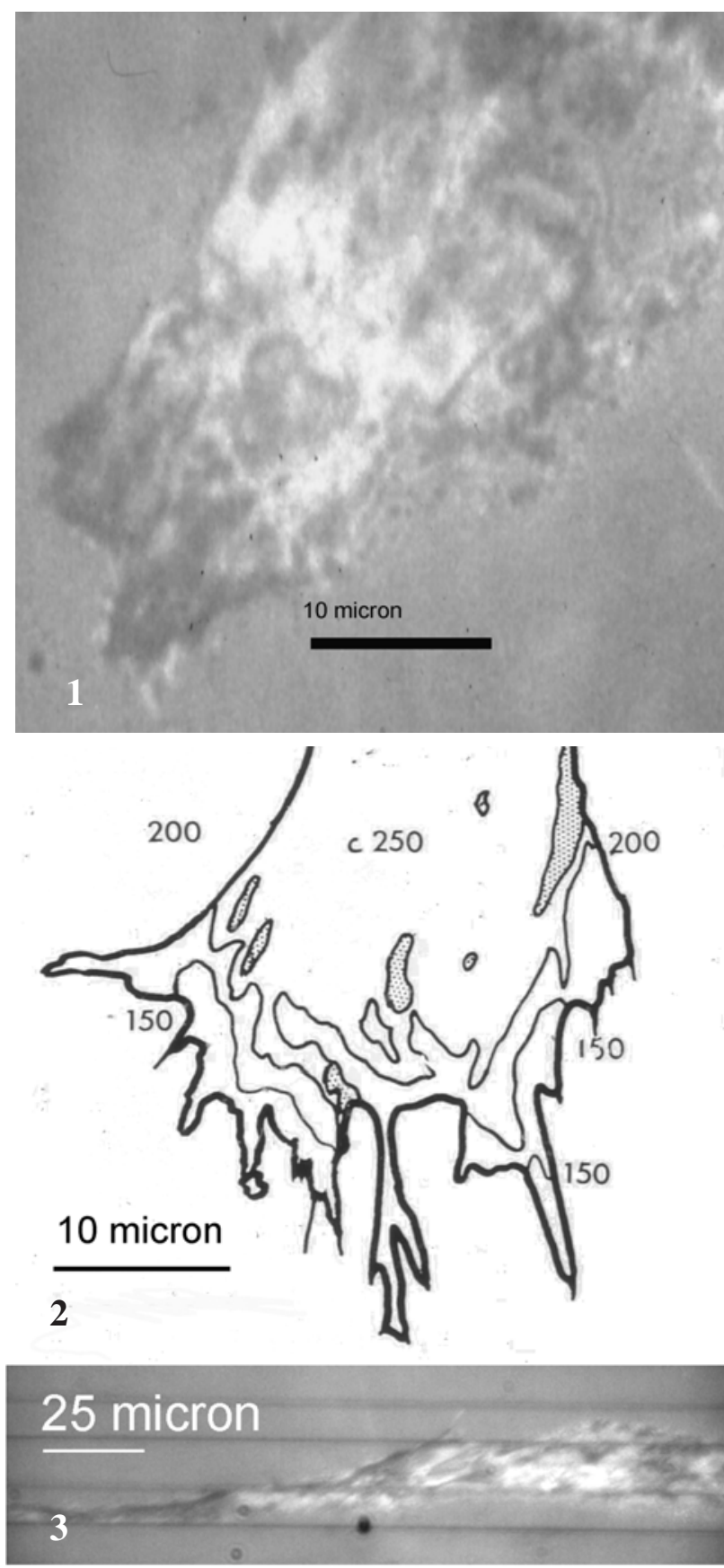

Figures 1-3. IRM images. Figure 1. Part of a fibroblast (chick), see Figure 2 for scale. The bar is $20 \mu \mathrm{m}$ long. Figure 2. Contact zone thickness (Contours in epitenon cell). Grooves $5 \mu \mathrm{m}$ wide. Figure 3. An epitenon fibroblast on $12.5 \mu \mathrm{m}$ wide groove/ridge silica substratum $100 \mathrm{~nm}$ deep. Note dark focal adhesions located near ridge-groove transition.

whether in shear flow or in Poiseuille flow in a tube, the shear rate in which the adhesions form can be known, thus the rate of formation of adhesions can be measured. It can be used to compare adhesive forces of differently sized particles. I introduced this method to cell biology using a Couette viscometer to provide the known shear rate (Curtis, 1969).

The translation of the collision efficiency into adhesive energies or forces requires an understanding of all the forces involved in forming and breaking an adhesion and 

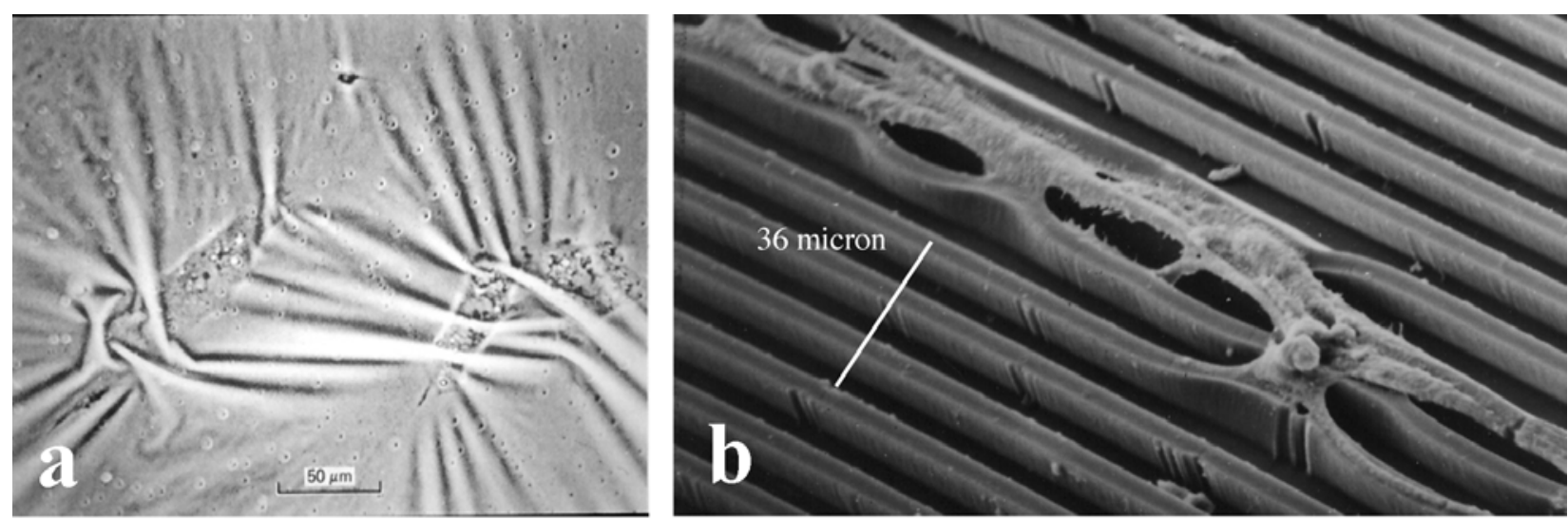

Figures 4a, b: Substrate distortion due to mechanical forces of contraction exerted by cells. LH image from Harris et al. (1980) by kind permission of Dr A. Harris. RH image of an epitenon cells on polyurethane grooves $5 \mu \mathrm{m}$ wide.

there are still some forces whose importance is unresolved. In better understood situations namely polystyrene microsphere suspensions, we (Curtis and Hocking, 1970) could measure forces of attraction. Incidentally this approach is capable of solving many problems - including why it rains, and if it does, why as large or small drops.

This type of approach looks at the earliest events in cell adhesion and at the shear rates used the collisional encounter can last less than 10 milliseconds. If the adhesion is formed within half the interaction time (as one cell (particle) rotates around the other, it tends to become permanent). Of course, not all particles collide at the same moment and in a dilute suspension it may take many minutes for sufficient collisions to occur to have much effect on adhesion. This gives a very different understanding of adhesion obtained from most biochemical experiments where the formation of adhesion may take many minutes. It is tempting to ask whether, in many of such experiments, that any effective treatment is the one that brings the cells into the state where they might adhere. This raises technical procedures about the preparation of cells (Curtis and McMurray, 1986).

Incidentally this same paper describes the use of attached beads for signalling to cells. The same fast formation of adhesions can be confirmed by IRM but we are yet to do the higher than normal frame rate video microscopy to time this. In practice in the body adhesions of platelets to blood vessels etc. or of embryonic tissues to each other but not of leucocytes to other cells (Jones et al., 1994) appears to take place very rapidly at the cell-by-cell level.

\section{Mechanotransduction}

My first post-doc job was with Michael Abercrombie trying to account for contact inhibition of movement, the phenomenon that many cell types display whereby they tend to cease crawling movement on contact. I found Michael a most inspiring research teacher who embued me with not a love or even a devotion to, but a belief that good experiments usually required good statistical testing. He generously encouraged me to work on adhesion and on cell surface grafting. Those were areas that were judged, probably correctly, to have little to do with contact inhibition. Nevertheless contact inhibition remained on the research agenda and this led me to investigate the related but almost converse situation whereby cells prefer to crawl on fibres and grooves. This had been discovered by Paul Weiss $(1945,1958)$ and I was intrigued as to why a change from a planar substrate to a grooved one made such large behavioural differences in cells. Weiss had proposed that the explanation for contact guidance was that the cells responded to molecular orientation of molecules adsorbed from the medium, the orientation being determined by adsorption reactions to curved surfaces. I felt that this could not be correct because the diameter of the fibres on which the phenomenon was most marked were very large compared with molecules. Malini Varde and I showed this experimentally (Curtis and Varde, 1964). No technique available at that time would have revealed molecular orientation to us, and even now arguably Atomic Force Microscopy (AFM) and Time of Flight Secondary Ion Mass Spectrometry (TOF-SIMS) might show orientation and tell us something about the molecules involved but would not provide that detailed molecular map of the surface that we desire. At the time we were not able to envisage a test that would tell us what force system aligned the cells but the problem remained. This was an early example of using a microfabricated environment for testing cells though the fabrication was in cellulose esters casts of diamond-ruled diffraction gratings. It was quite clear from observations by tissue culturerers that appreciable mechanical tensions developed in monolayers of cells and this was very well demonstrated by Albert Harris et al. (1980) (Fig. 4a, b).

When cultures are confluent they soon cease to divide and though Dunn and Ireland (1984) have explained this by diffusional limitations on the cells, I wondered if mechanical tension might be involved partly because of experiments on epithelial growth on artificially distended rat uteri. Experiments were designed and set up (Curtis and Seehar, 1978) using cells grown on fairly rigid nets distorted by piezo-device made from gas lighters. Results were definite that mechanical stimulation could stimulate the cell cycle. Mechanical stimulation would have stirred the medium so there might have been a diffusional component but the stimulation was such that very limited stirring took place. 


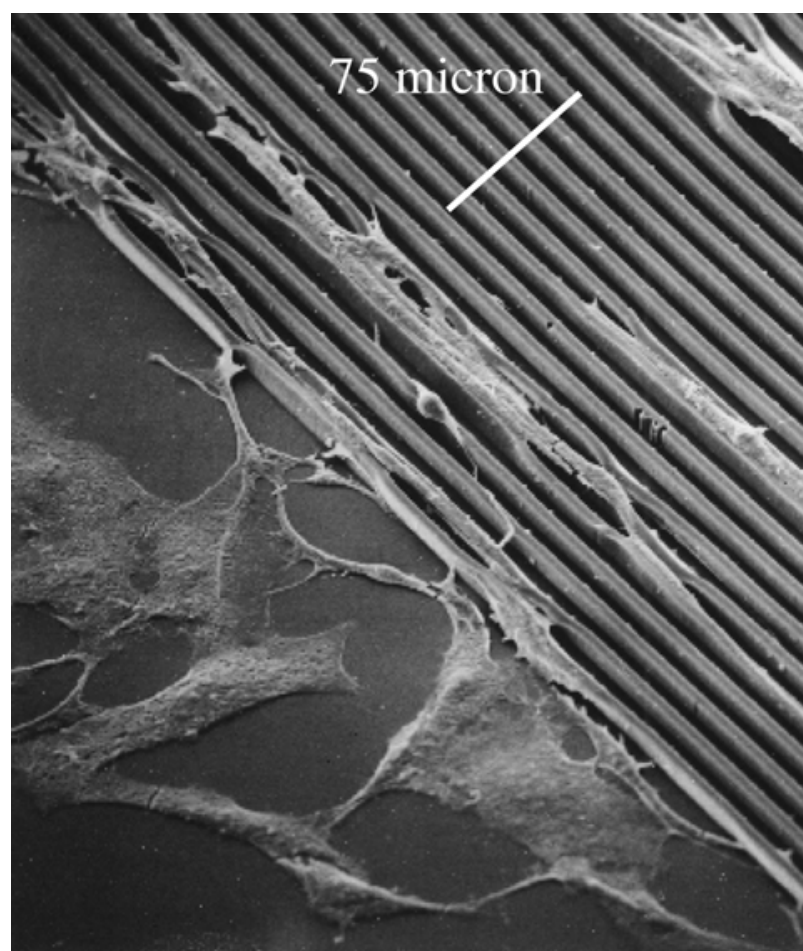

Figure 5. The reaction of rat epitenon fibroblasts to polyurethane (Elastane) grooves. Note the massive morphological changes comparing cells on the flat substratum and the grooved substratum. Also note that the cells appear to have distorted the ridges in places because of the cells' mechanical action. Scanning electron micrograph by Bill Monaghan.

\section{Micro and then Nano-Topography}

At this time, I really started work in earnest with Chris Wilkinson, who loves the small and the making of it, to explore the uses of microfabrication (and later nanofabrication) to make highly specified, if idealised, landscapes for cell resembling real tissue landscapes better than plastic culture dishes. Our collaboration has been stimulating and very productive and I am most grateful to Chris for all the interaction. We used photolithographic methods followed by dry etching to pattern silica, silicon, polymethylmethacrylate (PMMA) and by embossing from silica masters a range of polymers, for example polystyrene. Peter Clark joined us and this led to a thorough investigation of several different types and scales of structure (Clark, 1994; Clark et al., 1987, 1990, 1991). It is interesting that Brunette (Brunette et al., 1983) was carrying out similar work, though with titanium. Many papers were published, but even 15 years later many landscapes still remain to be investigated. One important thing that became clear was that many, perhaps all, types of cell tested were very reactive even to small differences in the scale of the topography (Fig. 5).

It was also clear that the reaction of the cells to topography involved the cytoskeleton of the cell to a marked extent (Fig. 6). One plausible explanation of these reactions were that the cells were exerting tensional forces on the substratum and reacting to the extent to which these forces were scaled by the substratum (Fig. 4). By this I mean that a distortable substrate will dissipate these forces
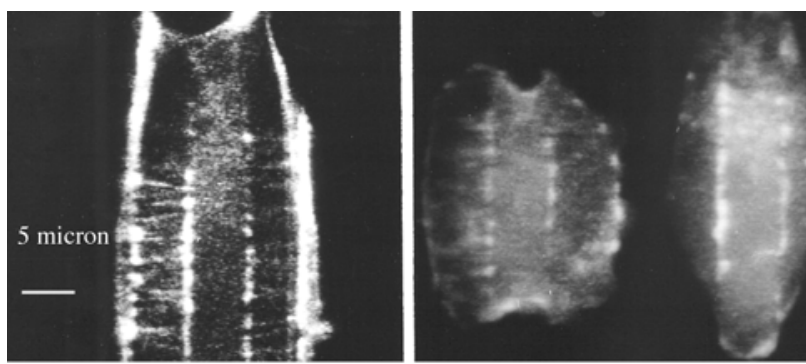

Figure 6. Actin organisation of cells reacting to $5 \mu \mathrm{m}$ wide grooves. LH image taxol poisoned. RH image colcemid poisoned.

over some distance whereas a hard substrate allows these forces to act directly on the surface which does not yield. Consequently, a hard substrate buried under a soft layer might be detected by the cells. Perhaps the most impressive demonstration of this was obtained by my present colleague, Mathis Riehle, who first conceived the possibility developing it from the idea of durotaxis (Lo et al., 2000), (Fig. 7). The figure shows that cells can react to the orienting signal of a hard silica grooved substrate separated from the cells by a layer about $10 \mu \mathrm{m}$ thick of much softer polydimethylsiloxane (PDMS). The cells show alignment to the underlying pattern indicating that they can sense the mechanical differences, in most cases cells assemble on the stiffer parts of the gel over the ridges. Some pictures show extensions especially along transitions. Several different cell eukaryote types were affected by some of the micro-topographies - indeed we could claim and still do, without having tested everything, that all eukaryote cell types so far examined (except red blood cells) will react to topography though the most effective dimensions vary from cell type to cell type, for a review see Curtis and Clark (1990). It is still debatable as to whether cells react to depth, groove width, discontinuities or combinations of these (Fig. 8).

Discontinuities, as at the intersection of two planes at 90 degrees, appear to form regions of high adhesion and preferential location of many cell types (Curtis and Clark, 1990; Curtis et al., 2004). Frequently cells migrate rapidly along these discontinuities. Figure 3 shows the formation of focal contacts along these edges. They also appear to be involved in actin organisation (Fig. 6). Similar reactions are seen at the zone of discontinuities, as at the zone of transition from a nanopatterned region to a planar one. Testing these ideas about cell orientation led Beata Wojciak-Stothard to look at the reaction of tendon cells to grooves and this produced such good 'reformation' of a tendon (Wojciak et al., 1995) in vitro that we designed and tested, with success, an in vivo system based on this.

When we turned to look at the reaction of neurons we found we could obtain very good guidance of neurons by grooves (Dow et al., 1987). This was not unexpected since Weiss had demonstrated this before 1960 (Weiss, 1945, 1958). From this grew a research programme on the building of nervous networks in culture. Chris Wilkinson and I were motivated by the desire, not yet fully satisfied, to examine how changes in connectivity of neurons may alter signal processing. This would provide a new 


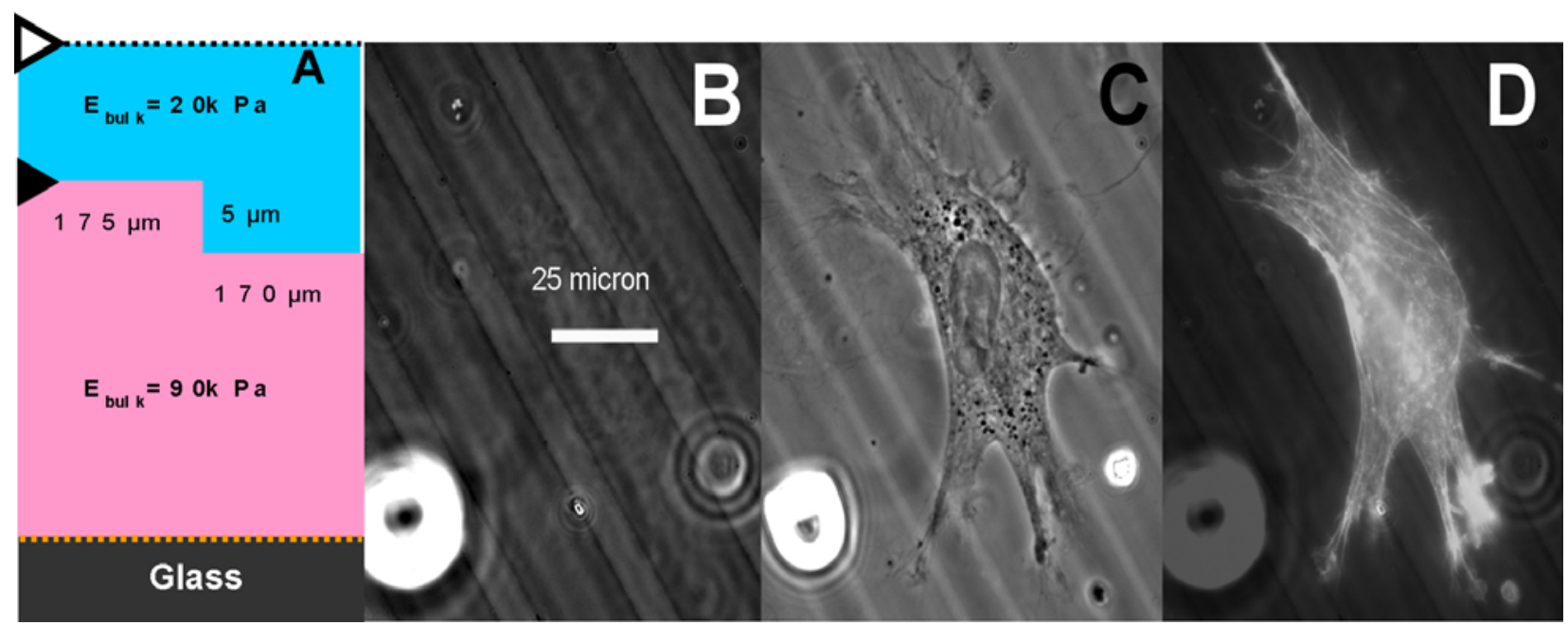

Figure: 7. Cells sensing "hidden" topography via changes in surface compliance. (A) A change of surface compliance can be designed by combining two materials of different mechanical property with topographic modulation: The lower "harder" gel with topography is overlaid with a softer, flat gel. A step height of $5 \mu \mathrm{m}$ leads to a change of apparent stiffness of $2 \%$ between "grooves" and "ridges". (B) Phase image focussed at the ridge level, 10 $\mu \mathrm{m}$ below the surface (indicated by a black triangle in A) showing the underlying groove pattern. (C) Phase image focussed at a cell on the top of the softer, flat gel (level indicated in A) by a white triangle. (D) F-actin within the cell shown in C. Courtesy of Dr M.O. Riehle

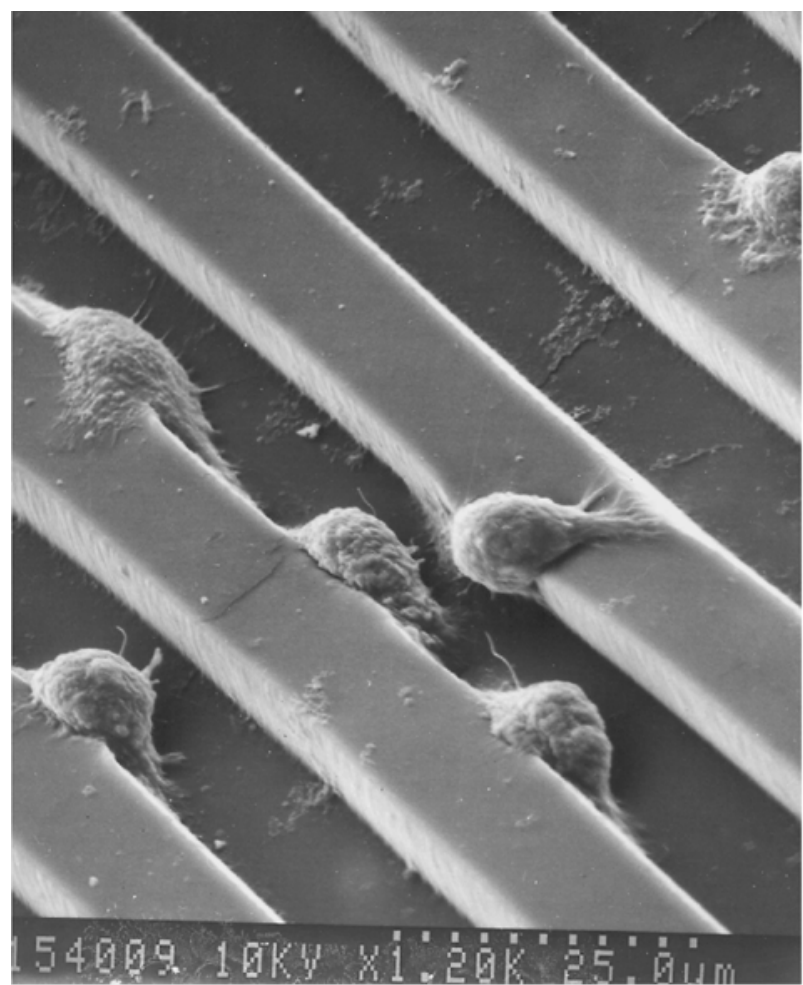

Figure 8. Human macrophages showing a preference for adhering and locating on the discontinuity between wall and top edge of ridges.

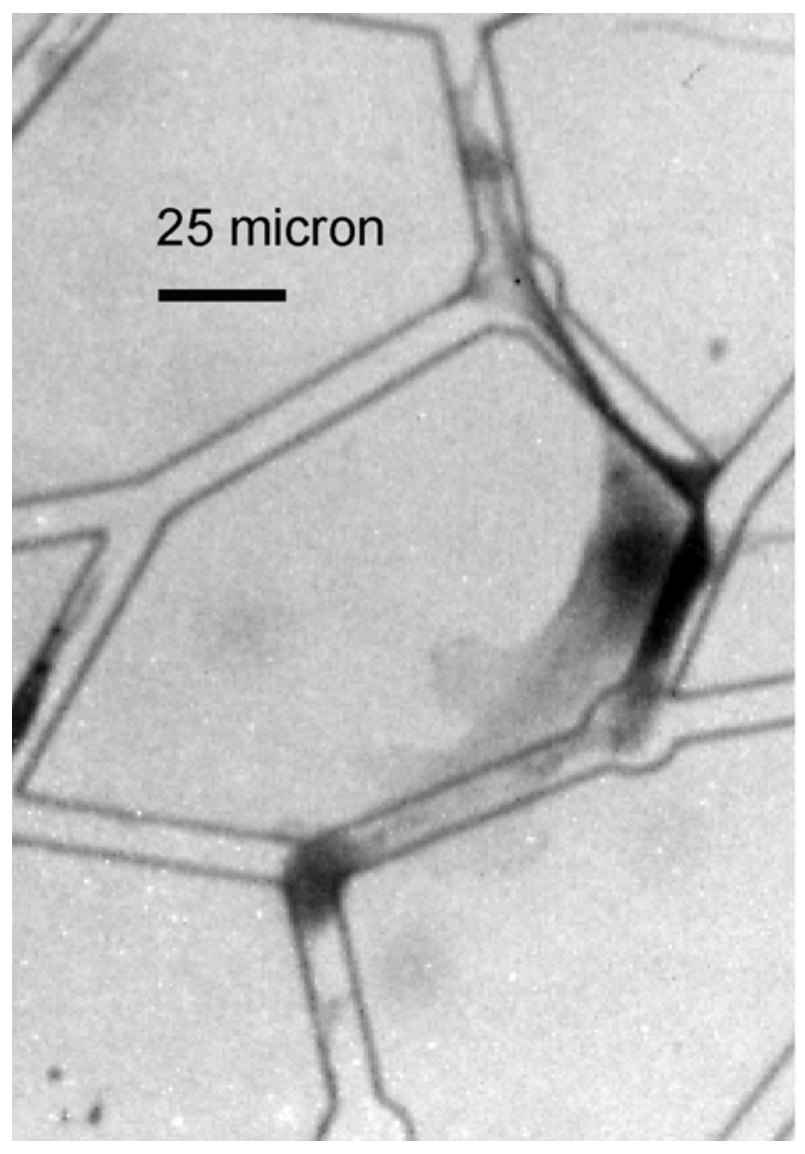

Figure. 9. Rat nodose ganglion neurites extending along grooves to form a linked linear network. One glial cell present as well. 5 micron wide grooves 
experimental material for neuroscientists intermediate in complexity between pairs of neurons and medium scale networks of cells of perhaps a 100 or 1000 neurons. Grooved substrates and also micro-contact printed patterns provided very good guidance (see Fig. 9) but there are still problems with extracting signals from these networks. These investigations have also led into theoretical studies on optimal network design (Wilkinson and Curtis, 1999).

Slightly earlier, while we were exploring the effects of groove and step dimensions on cell behaviour, we had found that effects seemed to become smaller as we approached dimensions of one micrometer. It seemed likely that effects might disappear in the nanometric region. Our colleague Peter Clark used a clever method of fabricating grooves only $130 \mathrm{~nm}$ wide by a photolithographic method and found that these had a very marked effect on cell orientation (Clark et al., 1991). Beata Wojciak-Stothard et al. (1996) showed that similar grooves of even smaller dimensions affected macrophage morphology and cell activity similarly strongly. Though we were making structures that were nanometric only in one dimension this encouraged us to set about making structures nanometric in all three dimensions. Fortunately, Chris Wilkinson has an electron beam lithographic (EBL) facility which was developing both in very advanced skills and in its equipment and at this point I should mention with much gratitude the especial skills of Brendan Casey, Bill Monaghan and Mary Robertson in these methods, without which the most recent five years of research would not have happened. It is worthwhile looking at the reviews by Chris Wilkinson for further information on development of EBL (Wilkinson et al., 2001; Wilkinson, 2004). Initially nanometric structures made by the EBL method came on line slowly and so we turned to a less precise or controllable but much faster method of fabrication. This was the polymer-demixing system. Fortunately, Dr Stanley Affrossman of Strathclyde University was a world expert on this technology and supplied us with many nanometric topographies in polymers (Affrossman and Stamm, 2000). Most of these had a single consistent surface chemistry an important point since chemical heterogeneity might have been expected but the topography was not fully defined. There then followed a long succession of papers mostly led by Matt Dalby (Dalby et al., 2002,a,b,c; Dalby et al., 2003 a,b; Dalby et al. 2004a,b) about the effects of nanotopography on cell shape, cytoskeletal organisation, cytokine production and most import of all, gene expression using microarray technology. We were encouraged in the last of these lines of research by the results of Chou et al. (1995) who showed that fibronectin expression was enhanced in cells grown on micrometric grooves. There were many changes in gene expression and it is perhaps too early to perceive clearly what is happening, Another of Matt Dalby's happy ideas was to look at filopodia on nanotopography which gave a strong idea that filopodia might be the 'organelle' that explores the nanoenvironment (Fig. 10).

The effects of nanotopography could be separated from effects of nanochemical patterns because (i) almost identical results could be obtained with the same patterns in a large range of polymers (ii) changing the proteins in

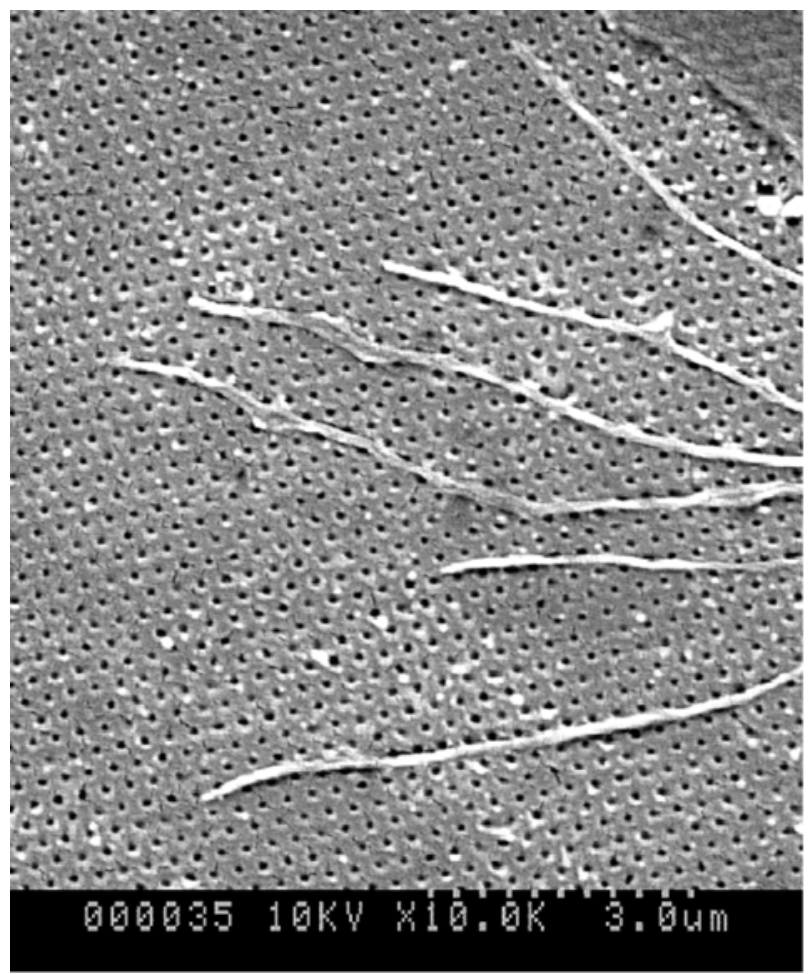

Figure 10. Scanning electron micrograph of Filopodia from an h-tert cell spreading over a hexagonally packed nanopit $300 \mathrm{~nm}$ centre to centre array showing relationship between filopodia and nanopits. Scale bar $2.4 \mu \mathrm{m}$. Reproduced with permission of Dr M. Dalby
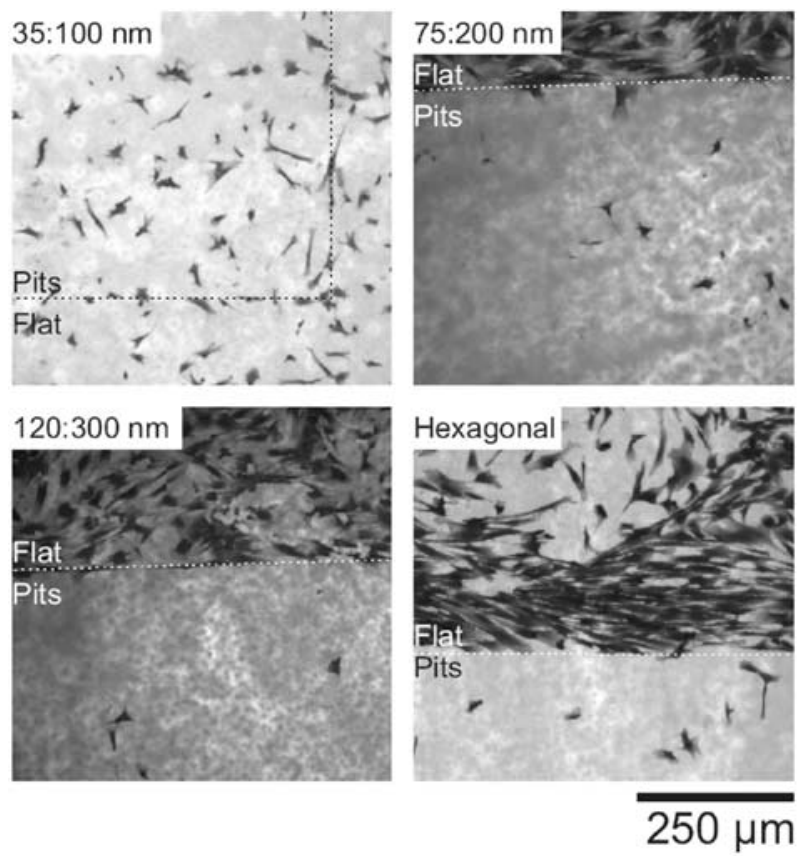

Figure 11. Rat epitenon cells grown on polycaprolactone surfaces for 24 hours, fixed and stained with Coomassie Blue. Each image shows the junction of a planar area and a nanopatterned area. The size and centre to centre spacing in $\mathrm{nm}$ of the nanopits is shown in the top LH corner of each separate image. Cells appear black. Note that with the exception of the smallest closest spaced pits adhesion of cells on the nanopatterned areas is very much lower than on the planar areas. 


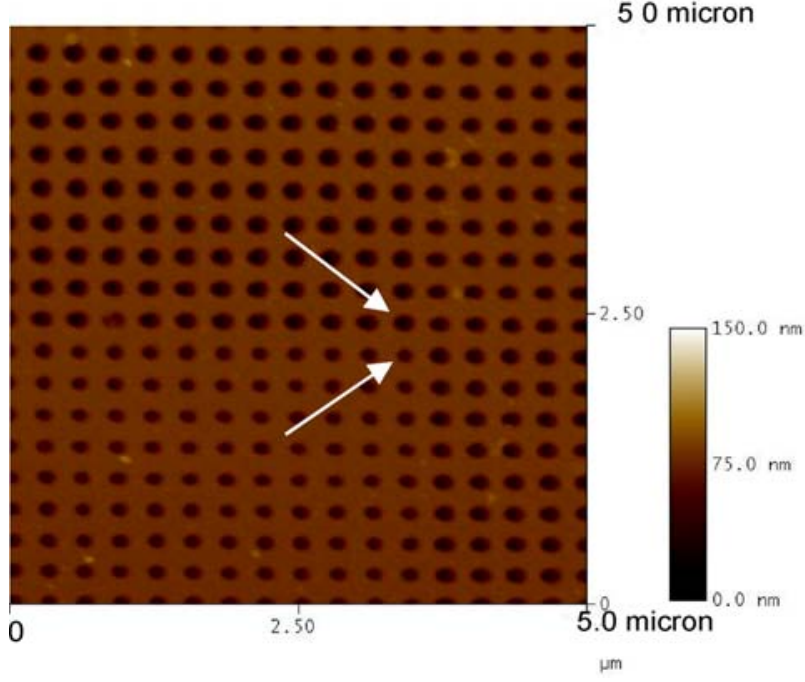

Figure 12. Defect in writing an array marked with white arrows that led to high adhesion locally. Defect was due to an error in Look-up Tables. $100 \mathrm{~nm}$ diameter pits on $300 \mathrm{~nm}$ spacing. Courtesy Dr N. Gadegaard.

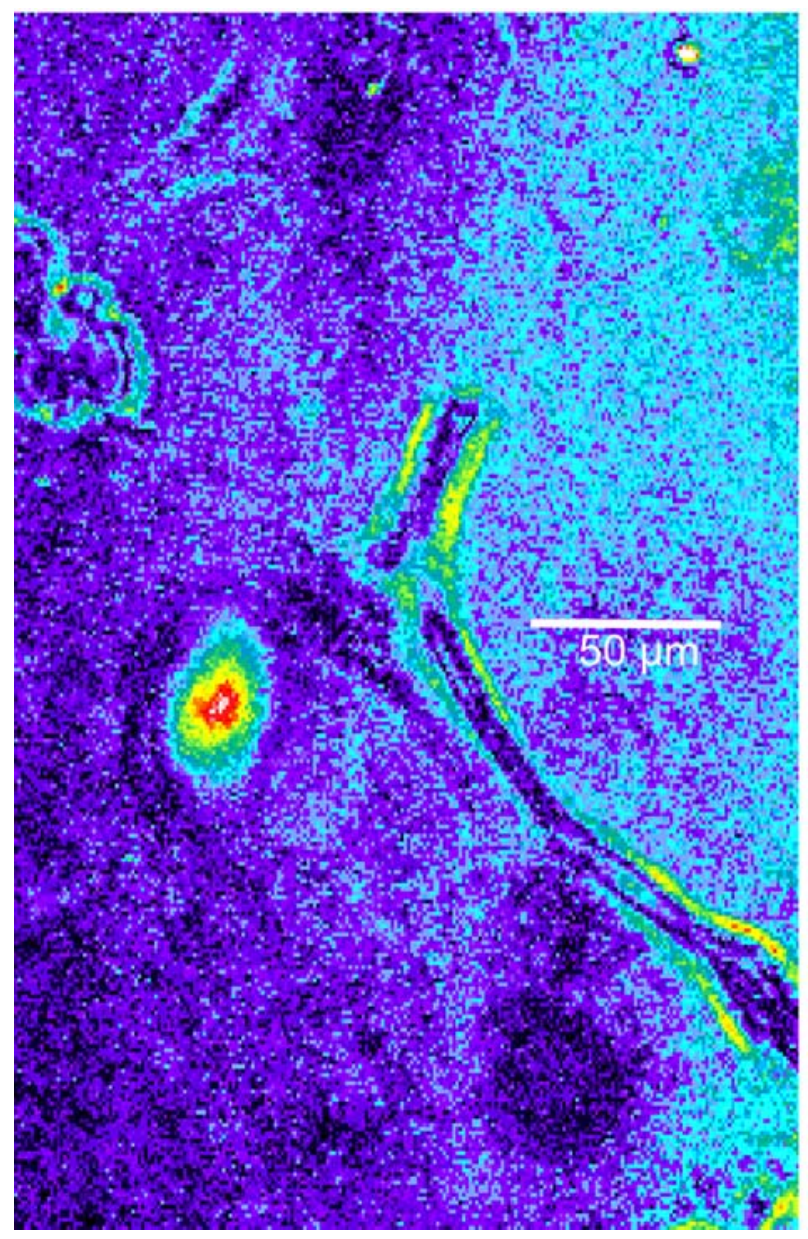

Figure 13. Photoelasticity used to measure forces developed by cells. Polydimethylsiloxane (PDMS) is the photoelastic material. Colour intensity represents retardance, hue represents azimuth. Note yellow bands on either side of cell near lamellipodium indicating strain in the substratum outside the cell. Bar $60 \mu \mathrm{m}$.

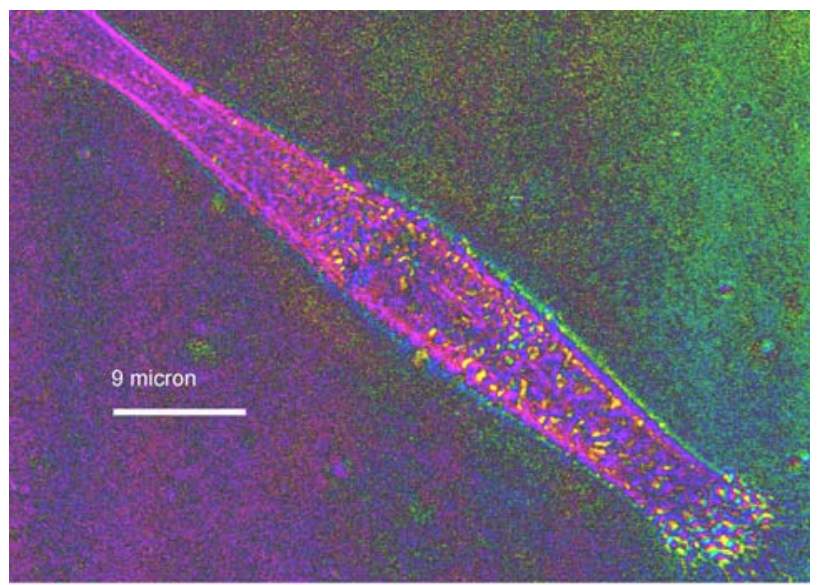

Figure. 14. Photoelastic effects in PDMS substrate induced by an $h$-tert cell. Pseudocolor as in Figure 13. Note strain effects around cell. Bar $20 \mu \mathrm{m}$. Courtesy of Theodora Tsapikouni.

the medium may have changed adsorption profiles but did not affect cell reaction. Some scientists have found this surprising, but the Riehle findings on mechanical properties of substrata provide an explanation as to why adsorption may not over-ride nanotopographical effects. Obviously the next stage will be to compare nanochemical patterns produced perhaps by contact printing with topographical patterns. When EBL produced patterns became available to us in relative abundance as a the result of the activities of Dr N.Gadegaard, we began to realise that in addition to the sizes of nanometric features their ordering was a important. Quasi-random patterns had small effects but precise orthogonal or hexagonal arrays of features had very obvious and relatively large effects (Curtis et al., 2004). Very small defects in these arrays lead to areas of high adhesion (Fig. 12).

At this point it is probably worth reminding readers that there is a great deal of nanometric detail in the environment of cells. Collagen provides an almost constantly present nanopatterned surface and other features such as cell contact zones are somewhat similarly patterned. All these results made us think about the cellular mechanism that might lead to these reactions of cells. Clearly the cytoskeleton was involved in the reactions. The ordered arrays showed sign of superhydrophobicity (Shiu et al., 2004) because these regularly ordered substrates of pits or pillars substrates are not wettable even though the materials from which they are made (e.g., clean silica) are wettable. Structures with sudden transition zones in the nanofeatures are highly adhesive for cells at these transitions and wettable. Incidentally such transition zones are hard to avoid since the 'stitch' regions in extensive nanopatterns usually show zones where the pattern changes in alignment or spacing over a pair of writing rows. The images of the zones of low adhesion show at their edges where they meet a planar surface, a region of high adhesion (Fig. 11). Liquid crystals placed on these nanometric surfaces show orientation effects (Flanders et al., 1978; Lay et al., 2000). Dr N. Gadegaard has started a programme of research using the AFM in the picoforce mode to search for such effects in water layers just above a 
nanotopographically patterned surface. Some work has been done on attempts to discover if changing the surface chemistry will over-ride the effects of nanotopography. (Nanomed report, web reference) and the conclusion is that extensive chemical changes will partially but not completely over-ride effects of topography.

\section{More Mechanical Transduction}

Thus there are reasons for suspecting that the reactions of cells to nanotopography are related to force interactions between substratum and cell and of course a component of these are the forces exerted by the cells on the substratum through their contractile mechanisms. These have recently been measured by a variety of techniques (Dembo et al., 1996. Balaban et al., 2001, Bershadsky et al., 2003) and can be as large as 1 nanoNewton per cell. It has been suggested that there may be a feedback system whereby resistance to cell motion results in an increase in cellular traction forces (Bershadsky et al., 2003). Dalby et al. (2003a,b) (following some preliminary work by Curtis (1994)) has explored the possibility that chromosome packing is altered by situations that change nuclear shape. This concept is originally based on the work of HeslopHarrison (Heslop-Harrison, 2003; Heslop-Harirsion et al., 1991) who showed that chromosome position in interphase nuclei is not random. From this one can conclude that conditions that alter nuclear shape are likely to alter chromosome packing and thus access of smaller molecules involved in transcription to various transcription sites. Dalby's results using chromosome painting techniques are yielding results persuasive that our expectations are being met.

These ideas lead to a further line of work, which is the measurement of the forces cells exert on the substratum and on each other. The methods of Dembo and of Balaban are most ingenious but appear to offer the cell cues that may change the forces the cells do exert. Furthermore there is the question of what lateral forces do cells exert on each other as they form a mono- or multilayer. Are these for example sufficient to alter gene expression? To this end, we have started using the very sensitive polarising microscope developed by CRI Instruments to measure photoelasticity in substrates induced by cellular stresses on the substratum materials (Fig. 13). Such techniques appear to allow the measurement of forces as small as $10^{-12}$ Newton per micrometer and show that force exertion by fibroblasts is not greatest at the tip of the lamellipodium but rather at the 'root' of the lamellipodium (Figs. 13 and 14). Since time-lapse videos can be taken using this technique it may become possible to reconstruct the history of the ways in which cells interact and possibly elucidate the events before cell division in a monolayer ceases.

This life review does not end with some majestic conclusions but dies away into the misty but tantalising future and thoughts of what might be done in some areas - that I feel is the essence of science - it is eternally on going.

\section{Adsorption Conundrum}

The adsorption of proteins and other large molecules onto surfaces made from polymers, silica, glass etc. presents a problem for those interested in cell attachment and behaviour. In a sense this must occur to some extent even for polyethylene-oxide like surfaces. So why do the cells apparently sense nanotopography? One explanation is the mechanical one advanced by Mathis Riehle (see above). Another is that an adsorbed layer even perhaps some 10nm thick still allows sufficient penetration by long range forces for underlying topography to effect interactions through it. A third less likely explanation is that the conformation of the adsorbed layer to the surface effectively transfers the surface to the adsorbed molecules while still preserving features of the original surface. What is clear is that existing methods for studying protein adsorption do not have the resolution, or capability for mapping individual species of molecule, or ability to provide information on conformation to be of real use. I hope these matters will be solved soon.

\section{Acknowledgments}

Besides those whom I have thanked in the main text I would like to express especial gratitude to Rose McKinney, Mike McGrath, Andrew Hart, Gregor Aitchison, Elizabeth Scott, Lucia Csaderova, Jeff Baxter, George Newell, Eric Lucey, Stan Affrossman and the forty-six Ph.D. students all of whom and my colleagues in various grants especially Steve Britland, Clive Evans, Julian Dow and the partners in the Bites, Nanomed and Magnanomed EC projects who did so much to make this research possible.

\section{References}

Affrossman S, Stamm M (2000) The effect of molecular weight an the topography of thin films of blends of poly(4bromostyrene) and polystyrene. Colloid Polym Sci 278: 888-893.

Balaban NQ, Schwarz US, Riveline D, Goichberg P, Tzur G, Sabanay U, Mahalu D, Safran S, Bershadsky A, Addadi L, Geiger B (2001) Force and focal adhesion assembly: a close relationship studied using elastic micropatterned substrates. Nature Cell Biol 3: 466-472.

Bershadsky A, Balaban D, Geiger B (2003) Adhesiondependent cell mechanosensitivity. Ann Rev Cell Dev Biol 19: $677-695$.

Bongrand P, Claesson PM, Curtis ASG (1994) Studying Cell Adhesion. Springer-Verlag, Berlin.

Brunette DM, Kenner GS, Gould TR (1983) Grooved titanium surfaces orient growth and migration of cells from human gingival explants J Dental Res 62: 1045-1048.

Chou L, Firth JD, Uitto V-J, Brunette DM (1995) Substratum surface topography alters cell shape and regulates fibronectin mRNA level mRNA stability secretion and assembly in human fibroblasts J Cell Sci 108: $1563-1573$. 
Clark P (1994) Cell behaviour on micropatterned surfaces Biosensors and Bioelectronics 9: 657-661.

Clark P, Connolly P, Curtis ASG, Dow JAT, Wilkinson CDW (1987) Topographical control of cell behaviour I Simple step cues. Development 99: 439-448.

Clark P, Connolly P, Curtis ASG, Dow JAT, Wilkinson CDW (1990) Topographical control of cell behaviour II Multiple grooved substrata. Development 108: 635-644.

Clark P, Connolly Curtis ASG, Dow JAT, Wilkinson CDW (1991) Cell guidance by ultrafine topography in vitro J Cell Sci 99: 73-77.

Curtis ASG (1964) The mechanism of adhesion of cells to glass J Cell Biol 20: 199-215.

Curtis ASG (1969) The measurement of cell adhesiveness by an absolute method J Embryol exp Morph 22: $305-325$

Curtis ASG (1994) Mechanical tensing of cells and chromosome arrangement Biomechanics and Cells (Soc for Exp Biol Seminar Series) 54: 54121-54130.

Curtis ASG, Clark P (1990)The effects of topographic and mechanical properties of materials on cell behaviour Critical Revs Biocompatibility 5: 343-362

Curtis ASG, Hocking LM (1970) Collision efficiency of equal spherical particles in a shear flow: The influence of London-Van der Waals Forces. Trans Faraday Soc 57066: 1381-1390.

Curtis ASG, Lackie JM (eds) (1991) Measuring Cell Adhesion. John Wiley Sons, Chichester.

Curtis ASG, McMurray H (1986) Conditions for fibroblast adhesion without fibronectin J Cell Sci 86: 25 33.

Curtis ASG, Seehar GM (1978) The control of cell division by tension or diffusion Nature 274: 52-53.

Curtis ASG, Varde M (1964) Control of cell behaviourtopological factors J Natl Cancer Inst 33: 15-26

Curtis ASG, Gadegaard N, Dalby M, Riehle MO, Wilkinson CDW, Aitchison G (2004) Cells react to nanoscale order and symmetry in their surroundings. IEEE Trans Nanobioscience 3: 61-65.

Dalby MJ, Childs S, Riehle MO, Johnstone H (2002a) Fibroblast reaction to island topography: changes in cytoskeleton and morphology with time. Biomaterials 24: 927-935

Dalby MJ, Riehle MO, Johnstone HJH, Affrossman S, Curtis ASG (2002b) in vitro reaction of endothelial cells to polymer demixed nanotopography. Biomaterials 23 : 2945-2954.

Dalby MJ, Riehle MO, Johnstone HJH, Affrossman S, Curtis ASG (2002c) Polymer-demixed nanotopography: Control of fibroblast spreading and proliferation. Tissue Engineering 8: 1099-1107.

Dalby MJ, Marshall GE, Johnstone HJH, Affrossman S, Riehle MO (2003a) Interaction of human and tissue cell types with $95 \mathrm{~nm}$ high nanotopography. IEEE Trans Nanobioscience 1: 18-23.

Dalby MJ, Riehle MO, Yarwood SJ, Wilkinson CDW, Curtis ASG (2003b) Nucleus alignment and cell signaling in fibroblasts : response to a micro-grooved topography. Exp Cell Res 284: 274-282.

Dalby MJ, Giannaras D, Riehle MO, Gadegaard N (2004a) Rapid fibroblast adhesion to $27 \mathrm{~nm}$ high polymer demixed nano-topography. Biomaterials 25: 77-83.

Dalby MJ, Riehle MO, Sutherland DS, Agheli H, Curtis ASG (2004b) Use of nano-topography to study mechanotransduction in fibroblasts - methods and perspectives. Eur J Cell Biol 83: 159-169.

Dan K (1947) Electrokinetic studies of marine ova VII Relation between zeta potential and adhesiveness of the cell membrane of sea-urchin eggs. Biol Bull 93: 274-282.

Dembo M, Oliver T, Ishihara A, Jacobson K (1996) Imaging the traction stresses exerted by locomoting cells with the elastic substratum method. Biophys J 70(4): 20082022.

Doroszewski J, Kiwala A (1988) Adhesion and locomotion of granulocytes under flow conditions. J Cell Sci 90: 335-340.

Dow JA, Clark P, Connolly P, Curtis ASG, Wilkinson CDW (1987) Novel methods for the guidance and monitoring of single cells and simple networks in culture. J Cell Sci 8: 55-79.

Dunn GA, Ireland GW (1984) New evidence that growth in 3T3 cell cultures is a diffusion-limited process. Nature 312: 63-65.

Duszyk MDJ, Doroszewski J (1986) Poiseuille flow method for measuring cell-to-cell adhesion Cell Biophys 8: 119-130.

Flanders DC, Shaver D, Smith HI (1978) Alignment of liquid crystals using submicrometer periodicity gratings. Appl Phys Lett 32: 597-598.

Gingell D (1981) The interpretation of interferencereflection images of spread cells: significant contributions from thin peripheral cytoplasm. J Cell Sci 49: 237-47.

Harris AKP, Wild P, Stopak D (1980) Silicone rubber substrata: a new wrinkle in the study of cell locomotion. Science 208: 177-179.

Heslop-Harrison JS (2003) Planning for remodelling nuclear architecture chromatin and chromosomes, Trends Plant Sci: 8: 195-197.

Heslop-Harrison JS, Mosgoller W, Schwarzacher T, Leitch AR (1991) Volumes and positions of chromosomes in reconstructions of fibroblasts. Am J Hum Genet 49:380 (abstr).

Izzard CS, Lochner LR (1976) Cell-to-substrate contacts in living fibroblasts: an interference reflexion study with an evaluation of the technique. J Cell Sci 21: 129-159.

Jones DA, McIntire LV, Smith CW, Picker LJ (1994) A two-step adhesion cascade for T-cell/endothelial cell interactions under flow conditions. J Clin Invest 94: 24432450

Kruyt HR (1949) Colloid Science. Vol 2. Elsevier, Amsterdam.

Kruyt HR (1952) Colloid Science. Vol 1. Elsevier, Amsterdam.

Lay E, Kirakosian A, Lin JL, Petrovykh DY, Crain JN, Himpsel FJ, Shah RR, Abbott NL (2000) Alignment of liquid crystals on stepped and passivated silicon templates prepared in ultrahigh vacuum. Langmuir 16: 6731-6738.

Lo CM, Wang HB, Dembo M, Wang YL (2000) Cell movement is guided by the rigidity of the substrate. Biophys J 79: 144-152. 
Richards RG, ap Gwynn I, Bundy KJ, Rahn BA (1995) Microjet impingement followed by scanning electron microscopy as a qualitative technique to compare cellular adhesion to various biomaterials. Cell Biol Int 19: 10151024.

Shiu JY, Kuo CW, Chen PL, Mou CY (2004) Fabrication of tunable superhydrophobic surfaces by nanosphere lithography. Chem Materials 16: 561-564.

Swift DL, Friedlander SK (1964) The coagulation of hydrosols by Brownian motion and laminar shear flow. J Coll Sci 19: 621-647.

Vitte J, Benoliel AM, Pierres A, Bongrand P (2004) Is there a predictable relationship between surface physicalchemical properties and cell behaviour at the interface? Eur Cell Mater 7: 52-63.

Weiss P (1945) Experiments on cell and axon orientation in vitro: the role of colloidal exudates in tissue organization. J Exp Zool 100: 353-386.

Weiss P (1958) Cell contact. Int Rev Cytol 7: 391-423.

Wilkinson CDW (2004) Making structures for Cell Engineering at Glasgow: Historical Review Eur Cell Mater 8: 21-26.

Wilkinson CDW, Curtis ASG (1999) Networks of living cells Physics World 12: 45-48.
Wilkinson CDW, Riehle MO, Wood M, Gallagher J, Curtis ASG (2001) The use of materials patterned on a nano- and micro-metric scale in cellular engineering Materials Science and Engineering 19:263-269.

Wojciak B, Crossan J, Curtis ASG, Wilkinson CDW (1995) Grooved substrata facilitate in vitro healing of completely divided flexor tendons. J Mater Sci: Mater in Medicine 6: 266-271.

Wojciak-Stothard B, Curtis ASG, Monaghan W, Macdonald K, Wilkinson CDW (1996) Guidance and activation of murine macrophages by nanometric scale topography Exp Cell Res 223: 426-435.

Zhang T, Morgan H, Curtis ASG, Riehle MO (2001) Measuring particle-substrate distance with surface plasmon resonance microscopy Optics A: Pure and Applied Optics 3: 333-337.

\section{Web References}

Nanomed report http://www.gla.ac.uk/centres/ cellengineering 